WAHANA

AKUNTANSI

Jumal Ilmiah
JURNAL ILMIAH WAHANA AKUNTANSI

Vol 13 (1) 2018, 58-69

http://journal.unj.ac.id/unj/index.php/wahana-akuntansi

\title{
PENGARUH PRODUK DOMESTIK REGIONAL BRUTO (PDRB), JUMLAH PENDUDUK DAN PAJAK HOTEL TERHADAP PENDAPATAN ASLI DAERAH (PAD)
}

\author{
Afifah Ariyani* \\ Fitri Yetti \\ Noegrahini Lastiningsih \\ Universitas Pembangunan Nasional "Veteran" Jakarta
}

\section{Article Info}

Keywords:

Local Revenue, Gross Regional Domestic Product, Population, Hotel Tax

\begin{abstract}
This research was conducted to examine the influence of Gross Regional Domestic Product, Population, and Hotel Tax on Local Revenue. Sample of this research uses Regency and City in Java Province from 2014 until 2016. Sampling technique using purposive sampling (purposive sampling method). There is 100 sam-ple of Regency and City in Java Province, resulted in 98 Regen-cy and City that are acceptable. Testing the hypothesis in this study using Multiple Linear Regression Analysis with SPSS 23 and a significance level of 5\%. The result of partial test showed that: (1) Gross Domestic Regional Product has a significant pos-itive influence on Local Revenue with a significance level of 0,000. (2) Population has a significant positive influence on Lo-cal Revenue with a significance level of 0,000. (3) Hotel Tax has a significant positive influence on Local Revenue with a signifi-cance level of 0,000.
\end{abstract}

\section{How to Cite:}

Ariyani, Afifah, Fitri Yetti, dan Noegrahini Lastiningsih. (2018). Pengaruh Produk Domestik Regional Bruto (PDRB), Jumlah Penduduk, dan Pajak Hotel Terhadap Pendapatan Asli Daerah (PAD). Jurnal Ilmiah Wahana Akuntansi, 13(1), 58-70. https:// doi.org/10.21009/ wahana.013.1.5 


\section{PENDAHULUAN}

Penyelenggaraan pemerintah daerah di Indonesia berdasarkan Undang-Undang Republik Indonesia Nomor 23 Tahun 2014 dilaksanakan melalui prinsip otonomi daerah yang berhak, berwenang, dan berkewajiban mengatur serta mengurus rumah tangganya sendiri. Adanya pelaksanaan otonomi daerah diharapan dapat mengurangi ketergantungan terhadap pemerintah pusat dan dapat meningkatkan kemandirian daerah. Untuk dapat melaksanakan dan membiayai penyelenggaraan pemerintah serta pembangunan daerahnya, setiap daerah diberikan sumber-sumber keuangan sesuai dengan potensi daerah masingmasing. Kemampuan daerah dalam menjalankan otonomi daerah dapat dilihat melalui keuangan daerahnya dengan memperhatikan besarnya jumlah Pendapatan Asli Daerah (PAD) yang diperoleh. Penerimaan daerah yang mencerminkan tingkat kemandirian daerah adalah pendapatan asli daerah, hal ini berarti semakin besar pendapatan asli daerah maka daerah tersebut semakin mandiri. Dengan meningkatnya pendapatan asli daerah diharapkan dapat meningkatkan kemakmuran dan kesejahteraan rakyat secara adil dan merata.

Beberapa indikator makro dapat digunakan untuk mengamati keberhasilan pembangunan dan kinerja perekonomian suatu daerah. Indikator makro tersebut yaitu Produk Domestik Regional Bruto (PDRB) yang dapat diartikan sebagai penjumlahan nilai tambah bruto dari seluruh unit kegiatan ekonomi yang beroperasi pada wilayah atau daerah tertentu serta dalam kurun waktu tertentu biasanya satu tahun. Ketika PDRB mengalami peningkatan maka pendapatan asli daerah akan meningkat karena menjadi tolok ukur pendapatan masyarakat dan pendapatan asli daerah.

Jumlah penduduk sangat mempengaruhi besarnya pendapatan asli daerah ketika jumlah penduduk meningkat maka semakin banyak pula masyarakat yang berbelanja, dengan banyaknya barang dan jasa yang dikonsumsi oleh masyarakat akan menyebabkan perkembangan usaha-usaha di daerah tersebut semakin baik, dimana ketika usaha semakin besar jumlah pajak yang dibayarkan kepada pemerintah semakin tinggi.

Pajak hotel yang potensinya semakin berkembang seiring dengan semakin diperhatikannya komponen pendukung yaitu sektor jasa dan pariwisata dalam kebijakan pembangunan daerah. Pajak hotel memberikan kontribusi nyata terhadap nilai pajak daerah sehingga ketika pajak hotel mengalami

peningkatan maka akan meningkatkan pendapatan asli daerah. Namun pada faktanya masih ada daerah yang Pendapatan Asli Daerah (PAD) mengalami penurunan yaitu Kota Tasikmalaya dimana pada tahun 2014 PAD nya sebesar Rp253.450.505.788,21 sedangkan pada tahun 2015 PADnya sebesar Rp242.979.820.517,50, walaupun PDRB, jumlah penduduk dan pajak hotel ngalami peningkatan. Dimana PDRB pada tahun 2014 sebesar Rp13.623.772,90 sedangkan pada tahun 2015 sebesar Rp15.234.112,0, jumlah penduduk pada tahun 2014 sebesar 654.794 jiwa sedangkan pada tahun 2015657.477 jiwa, dan pajak hotel pada tahun 2014 sebesar Rp2.236.970.016 sedangkan pada tahun 2015 Rp2.294.530.818. 


\section{TINJAUAN PUSTAKA, KERANGKA PEMIKIRAN DAN HIPOTESIS Kerangka}

\section{Teori}

Berdasarkan kerangka pemikiran kaitan variabel independen Produk Domestik Regional Bruto (PDRB), Jumlah Penduduk, dan Pajak Hotel dengan variabel dependen Pendapatan Asli Daerah (PAD) dapat didukung dengan teori stakeholder dan untuk variabel Pendapatan Asli Daerah dapat didukung juga dengan teori stewardship. Teori Stakeholder memiliki asumsi bahwa pihak berkepentingan terhadap organisasi dapat mengendalikan atau mempunyai kemampuan untuk mempengaruhi keputusan pemakai sumber-sumber ekonomi yang digunakan. Dengan adanya pihak-pihak berkepentingan diharapkan dapat membuat kebijakan dan mengambil keputusan yang tepat mengenai pengelolaan keuangan daerah agar optimal sesuai dengan sumber daya yang ada di daerahnya, terutama dalam pengelolaan pendapatan asli daerah.

Hubungan teori stakeholder dengan produk domestik regional bruto terhadap pendapatan asli daerah adalah pihak-pihak berkepentingan dapat membuat kebijakan yang tepat besarnya nilai tambah yang akan ditambahkan pada setiap produk, ketika nilai yang ditambahkan lebih besar maka pajak yang ditarik lebih besar sehingga dapat meningkatkan pendapatan asli daerah.

Hubungan teori stakeholder dengan jumlah penduduk terhadap pendapatan asli daerah adalah pihak-pihak berkepentingan dapat mengatur laju pertumbuhan penduduk dengan pengambilan kebijakan yang tepat, agar jumlah penduduk dapat dikendalikan dan memiliki kualitas yang baik, penduduk dengan kualitas yang baik dapat meningkatkan nilai produksi sehingga pendapatan yang diperoleh lebih besar. Ketika pendapatan penduduk besar tingkat konsumsi akan semakin besar hal ini akan berpengaruh terhadap perkembangan usaha disekitar. Dengan semakin besar suatu usaha pajak yang harus dibayar semakin besar dimana akan meningkatkan pendapatan asli daerah.

Hubungan teori stakeholder dengan pajak hotel terhadap pendapatan asli daerah adalah pihak-pihak berkepentingan dapat mengatur atau mengambil keputusan mengenai pengelolaan hotel yang ada pada daerahnya. Ketika hotel dikelola dengan baik maka pajak hotel yang di terima akan semakin tinggi karena aturan yang berlaku lebih jelas sehingga akan memberikan kontribusi yang maksimal untuk pendapatan asli daerah.

Teori stewardship mempunyai asumsi bahwa pihak yang mengatur atau mengelola jalannya suatu organisasi tidak memiliki kepentingan individu tetapi lebih mengutamakan kepentingan organisasi. Keterkaitan teori stewardship dengan pendapatan asli daerah adalah ketika pihak pengelola tidak mementingkan tujuan individu diharapkan penerimaan pendapatan asli daerah lebih maksimal dengan adanya kebijakan yang tepat. ketika pengelola lebih mementingkan kepentingan individu dapat menyebabkan banyak terjadinya kecurangan.

\section{Pengembangan Hipotesis}

PDRB merupakan pendapatan total yang di

ISSN: 
peroleh secara domestik, termasuk pendapatan yang diperoleh dari faktor-faktor produksi yang dimiliki asing, pengeluaran total atas barang dan jasa yang diproduksi secara domestik atau nilai pasar semua barang dan jasa akhir yang di produksi dalam perekonomian selama kurun waktu tertentu. Keterkaitan antara PDRB sebagai tolok ukur pendapatan masyarakat dengan Pendapatan Asli Daerah (PAD), semakin tinggi pendapatan seseorang maka semakin tinggi pula seseorang membayar pajak yang telah ditetapkan pemerintah. Pada tingkat distribusi pendapatan tertetu yang tetap, semakin tinggi produk domestik regional bruto per kapital riil suatu daerah, akan semakin besar pula kemampuan masyarakat untuk membiayai pengeluaran rutin dan pengeluaran pembangunan pemerintah (Atmaja, 2007 dalam Mayza, dkk 2015). Produk domestik regional bruto sebagai nilai tambah barang dan jasa sehingga dapat meningkatkan pendapatan asli daerah (Elita, 2007 dalam Jaya \& Widanta, 2014).

$\mathrm{H}_{1}$ : Produk Domestik Regional Bruto berpengaruh signifikan terhadap Pendapatan Asli Daerah

Jumlah penduduk merupakan salah satu faktor yang membedakan pendapatan antar daerah. Peningkatan jumlah penduduk dibutuhkan dan bukan suatu masalah, melainkan untuk merangsang pembangunan dan pertumbuhan ekonomi dengan membuat suatu perencanaan pembangunan. Penduduk sebagai sumber daya utama yang berpengaruh besar terhadap pembangunan di suatu wilayah (Population Reference Bureau (PRB), 2011 dalam Asmuruf, dkk 2015). Keterkaitan antara jumlah penduduk dengan Pendapatan Asli Daerah (PAD) yaitu besarnya pendapatan dapat dipengaruhi oleh jumlah penduduk. Akan tetapi pertumbuhan penduduk tidak mempengaruhi pendapatan secara proposional (Atmaja, 2007 dalam Mayza, dkk 2015). Ketika jumlah penduduk meningkat maka pendapatan yang ditarik juga akan meningkat (Simanjuntak, 2001 dalam Asmuruf, dkk 2015).

$\mathrm{H}_{2}$ : Jumlah Penduduk berpengaruh signifikan terhadap Pendapatan Asli Daerah

Hotel merupakan salah satu sektor yang berkaitan langsung dengan industri pariwisata dimana saat ini industri pariwisata semakin berkembangan, ketikan semakin banyak yang menyewa hotel maka semakin banyak pajak hotel yang diterima sehingga pendapatan asli daerah akan meningkat. Pajak hotel termasuk jenis pajak daerah. Pajak daerah adalah salah satu komponen pendapatan asli daerah dimana pajak sebagai sumber pendapatan utama untuk membiayai kegiatan pemerintah dalam menyediakan kebutuhan-kebutuhan yang tidak dihasilkan oleh swasta. Sehingga pajak hotel yang merupakan salah satu sumber keuangan daerah untuk peningkatan pendapatan asli daerah (Rustanto, dkk 2013).

H3: Pajak Hotel berpengaruh signifikan terhadap Pendapatan Asli Daerah

\section{OBJEK DAN METODOLOGI PENELITIAN}

Penelitian ini dilakukan pada Kabupaten dan Kota di Provinsi Jawa tahun 2014-2016, pemilihan sampel menggunakan purposive sampling sehingga dari 100 Kabupaten dan Kota di Provinsi Jawa, hanya 98 Kabupaten dan Kota

ISSN: 
yang menjadi objek pada penelitian ini. Data yang digunakan adalah data sekunder yang didapat dari BPK dan website BPS www.bps.go.id berupa laporan keuangan pemerintah daerah, laporan besarnya PDRB dan laporan hasil sensus penduduk. Adapun kriteria yang digunakan dalam penelitian ini adalah kabupaten dan kota yang sudah menyampaikan Laporan Keuangan Pemerintah Daerah (LKPD) pada tahun 2014-2016 ke Badan Pemeriksa Keuangan (BPK), kabupaten dan kota yang Laporan Keuangan Pemerintah Daerah (LKPD) pada tahun 2014-2016 telah di audit oleh Badan Pemeriksa Keuangan (BPK), kabupaten dan Kota yang dalam Laporan Keuangan Pemerintah Daerah (LKPD) mencantumkan besar pajak hotel pada tahun 2014-2016, kabupaten dan kota yang mempublikasikan besarnya PDRB pada tahun 2014-2016, serta kabupaten dan kota yang sudah melakukan sensus penduduk dan mempublikasikannya pada tahun 2014-2016.

Pendapatan Asli Daerah (PAD) adalah hak pemerintah daerah yang diakui sebagai penambahan nilai kekayaan yang bersih (Asmuruf, dkk 2015). Pendapatan Asli Daerah (PAD) diukur dari hasil realisasi pendapatan asli daerah kabupaten dan kota yang terdiri dari hasil pajak daerah, retribusi daerah, hasil pengelolaan kekayaan daerah yang dipisahkan dan lain-lain pendapatan asli daerah yang sah.

Produk Domestik Regional Bruto (PDRB) adalah total nilai barang dan jasa yang diproduksi pada wilayah (regional) tertentu selama kurun waktu tertentu (satu tahun) (Asmuruf, dkk 2015). Produk domestik regional bruto dilihat dari produk domestik regional bruto kabupaten dan kota. Pengukuran untuk produk domestik regional bruto yaitu menggunakan PDRB dengan harga berlaku, melalui pendekatan produksi.

Jumlah penduduk adalah jumlah manusia yang bertempat tinggal/berdomisili di suatu wilayah atau daerah dan memiliki mata pencarian tetap pada daerah tersebut serta tercatat dengan sah berdasarkan peraturan yang berlaku (Asmuruf, dkk 2015). Jumlah penduduk diukur dalam satuan jiwa yang bertempat tinggal/berdomisili di kabupaten dan kota.

Pajak Hotel merupakan setiap pelayanan yang disediakan hotel dengan pembayaran dipungut pajak dan jasa penunjang sebagai kelengkapan hotel yang sifatnya memberikan kemudahan dan kenyamanan (Rustanto, dkk 2013). Pajak hotel di ukur berdasarkan realisasi penerimaan pajak hotel kabupaten dan kota.

Dari keempat variabel tersebut skala yang digunakan adalah rasio dan Data yang diteliti terjadi perbedaan satuan sehingga diperlukan transformasi data ke dalam bentuk logaritma berganda dengan menggunakan logaritma natural (ln) (Gujarati, 1991 dalam Asmuruf, dkk 2015).

Teknik analisis data yang digunakan dalam penelitian ini dilakukan dengan menggunakan analisis regresi linear berganda yang dapat mengukur kekuatan hubungan antara dua variabel atau lebih, dengan dibantu program komputer yaitu SPSS 23 dan Microsoft Excel 2016 serta untuk membuktikan hipotesis yang telah dibuat, maka dilakukan pengujian hipotesis secara individual atau parsial (uji t) dan uji 
koefisien determinasi $\left(\mathrm{R}_{2}\right)$, namun sebelum melakukan uji hipotesis harus dilakukan uji asumsi klasik yaitu uji multikolonieritas, uji autokorelasi, uji heteroskedastisitas dan uji normalitas serta dilakukan uji statistik deskriptif. Persaman regresi linier berganda pada penelitian ini adalah:

$$
\mathrm{LnY}=\beta_{0}+\beta_{1} \ln \mathrm{X}_{1}+\beta_{2} \ln \mathrm{X}_{2}+\beta_{3} \ln \mathrm{X}_{3}+\mathrm{e}
$$

Keterangan :

$\mathrm{Y}=$ Pendapatan Asli Daerah (PAD)

$\beta_{0}=$ Konstanta

$\mathrm{X}_{1}=$ Produk Domestik Regional

Bruto $\mathrm{X}_{2}=$ Jumlah Penduduk $\mathrm{X}_{3}=$

Pajak Hotel

$\beta_{1} \beta_{2} \beta_{3}=$ Koefisien regresi untuk

masingmasing variabel independen

$\mathrm{e}=$ Error $($ variabel gangguan $)$

\section{PEMBAHASAN}

\section{Hasil Statistik Deskriptif}

Tabel 1 di bawah ini merupakan hasil uji statistik deskriptif dari penelitian ini dari data yang belum di outlier.

\section{Tabel 1}

\section{Uji Statistik Deskriptif Sebelum Outlier}

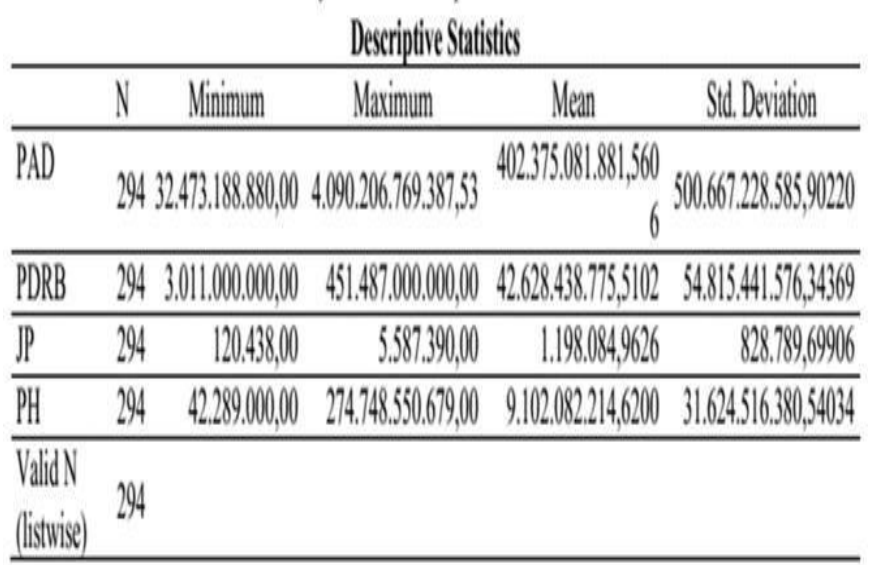

Sumber: Data Diolah Penulis, Tahun 2018

Dari Tabel 1 diatas dapat diketahui bahwa sampel yang digunakan sejumlah 294 yang berasal dari 98 Kabupaten dan Kota dengan periode penelitian 3 tahun yaitu tahun 20142016. Tabel 1 di atas merupakan hasil data sebelum di outlier. Berdasarkan hasil pengolahan data dengan IBM SPSS versi 23 diketahui bahwa pada saat dilakukan uji asumsi klasik data dalam penelitian tidak terdistribusi secara normal dan terkena heteroskedastisitas, dimana beberapa data yang diteliti terlalu ekstrim nilainya yaitu terlalu tinggi dan terlalu rendah sehingga data yang digunakan di outlier terlebih dahulu.

Tabel 2 di bawah ini merupakan hasil uji statistik deskriptif dari penelitian ini dari data yang belum di outlier.

\section{Tabel 2}

\section{Uji Statistik Deskriptif Sebelum Outlier}

\begin{tabular}{|c|c|c|c|c|c|}
\hline \multicolumn{6}{|c|}{ Descrintive Statistics } \\
\hline & $\mathrm{N}$ & Minimum & Maximum & Mean & Std. Deviation \\
\hline PAD & 230 & $101.276 .945 .021,59$ & $\begin{array}{r}702.055 .372 .759,0 \\
8\end{array}$ & $278.810 .776 .254,6199$ & 108.115.039.977,22414 \\
\hline PDRB & 230 & $7.093,000,000,00$ & $\begin{array}{r}114.8820000000,0 \\
0\end{array}$ & $31.989 .191 .304,3478$ & $22.787 .529 .692,99425$ \\
\hline $\mathbb{P}$ & 230 & $2780.072,00$ & $3,470,393,00$ & $1.127 .128,9696$ & $526.222,10809$ \\
\hline PH & 230 & $42.289,000,00$ & $39.3559 .966 .312,61$ & $2.577 .949 .178,0152$ & $4.939,377,417,57083$ \\
\hline $\begin{array}{l}\text { ValidN } \\
\text { (istwise) }\end{array}$ & 230 & & & & \\
\hline
\end{tabular}

Sumber: Data Diolah Penulis, Tahun 2018

Dari Tabel 2 di atas dapat diketahui bahwa sampel yang digunakan sejumlah 230 yaitu data setelah dilakukan outlier.

\section{Uji Multikolonieritas}

Hasil uji multikolinieritas dari penelitian ini menunjukkan bahwa data dalam penelitian tidak terkena multikolonieritas dimana nilai tolerance lebih besar dari 0,10 dan nilai VIF lebih kecil dari 10, artinya produk domestik regional bruto, jumlah penduduk, dan pajak hotel adalah independen, tidak memiliki keterkaitan

ISSN: akuntansi/13.1.05 
satu sama lain. Produk domestik regional bruto bukan bagian dari jumlah penduduk dan pajak hotel begitu pula sebaliknya.

Tabel 3 di bawah ini merupakan hasil uji multikolinearitas dari penelitian ini.

Tabel 3

\section{Hasil Uji Mutlikolonieritas}

Coefficients

\begin{tabular}{|l|l|r|r|}
\hline & \multicolumn{3}{|c|}{ Collinearity Statistics } \\
\hline Model & & Tolerance & VIF \\
\hline \multirow{3}{*}{1} & (Constant) & & \\
\cline { 2 - 4 } & PDRB &, 581 & 1,720 \\
\cline { 2 - 4 } & JP &, 710 & 1,408 \\
\hline & PH &, 790 & 1,266 \\
\hline
\end{tabular}

a. Dependent Variable: PAD Sumber:

Data Diolah Penulis, Tahun 2018

\section{Uji Autokorelasi}

Tabel 4 di bawah ini merupakan hasil uji multikolinearitas dari penelitian ini.

\section{Tabel 4}

\section{Hasil Uji Autokorelasi}

Model Summary

\begin{tabular}{|c|c|}
\hline Model & Durbin-Watson \\
\hline 1 &, 849 \\
\hline
\end{tabular}

a. Predictors: (Constant), PH, JP, PDRB

b. Dependent Variable: PAD

Sumber: Data Diolah Penulis, Tahun 2018

Berdasarkan Tabel 4 di atas hasil data setelah di outlier menunjukkan bahwa data dalam penelitian tidak terkena autokorelasi dimana nilai dari DW tidak lebih kecil dari -2 dan tidak lebih besar dari +2 atau $-2<$ DW $<+2$, artinya bahwa antara data tahun 2014 sampai dengan tahun 2016 untuk variabel produk domestik regional bruto, jumlah penduduk dan pajak hotel tidak saling berhubungan atau tidak terkait antara tahun sekarang dengan tahun sebelumnya.

\section{Uji Heteroskedastisitas}

Gambar 1 di bawah ini merupakan hasil uji heteroskedastisitas dari penelitian ini.

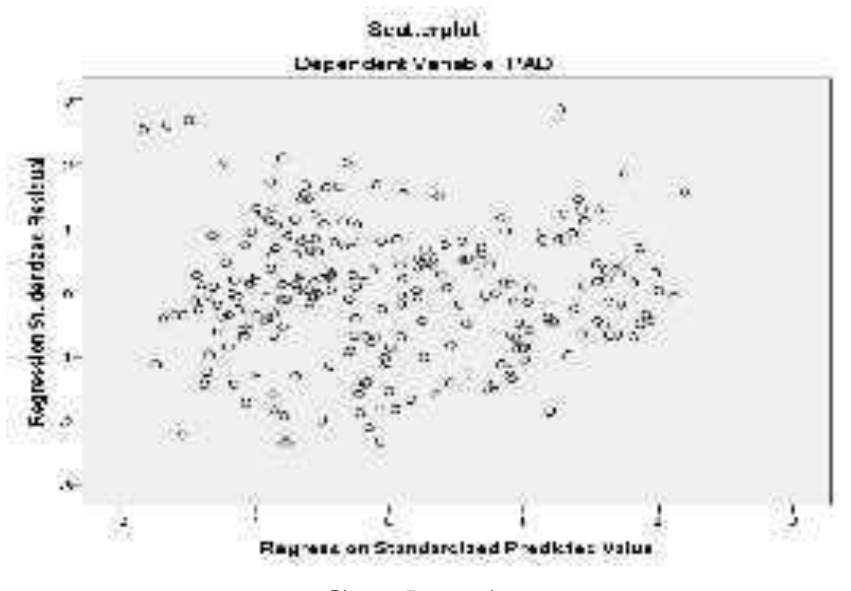

Gambar 1

\section{Hasil Uji Heteroskedastisitas}

Sumber: Data Diolah Penulis, Tahun 2018

Berdasarkan Gambar 1 di atas terlihat bahwa titik-titik menyebar secara acak dan tidak membentuk sebuah pola tertentu yang jelas, serta tersebar baik diatas maupun dibawah angka 0 pada sumbu Y. Hal ini menunjukkan bahwa tidak terjadi Heteroskedastisitas pada model regresi ini artinya sudah tidak terdapat keragaman data pada produk domestik regional bruto, jumlah penduduk dan pajak hotel terhadap pendapatan asli daerah.

\section{Uji Normalitas}

Tabel 5 di bawah ini merupakan hasil uji normalitas dari penelitian ini. 
Tabel 5

\section{Hasil Uji Normalitas}

\begin{tabular}{llr} 
N & & 230 \\
\hline Normal & Mean &, 0000000 \\
\cline { 2 - 3 } Parameters & & Std. Deviation \\
\hline Most Extreme & Absolute &, 21685629 \\
\cline { 2 - 3 } Differences & Positive &, 041 \\
\cline { 2 - 3 } & Negative &, 041 \\
\hline Test Statistic & &,- 031 \\
\hline Asymp. Sig. (2-tailed) & &, 041 \\
\hline
\end{tabular}

a. Test distribution is Normal.

b. Calculated from data.

c. Lilliefors Significance Correction.

$d$. This is a lower bound of the true significance.

Sumber: Data Diolah Penulis, Tahun 2018

Berdasarkan Tabel 5 di atas diketahui bahwa nilai Asymp.sig adalah 0,200. Dapat dikatakan bahwa data terdistribusi normal dan memenuhi asumsi normalitas karena nilai yang diperoleh pada Asymp.sig lebih besar dari 0,05 $(0,200>0,05)$, artinya secara simultan model yang digunakan dalam penelitian ini untuk pendapatan asli daerah berdistribusi normal.

\section{Uji Koefisien Determinasi}

Tabel 6 di bawah ini merupakan hasil uji koefisien determinasi dari penelitian ini.

Tabel 6

\section{Hasil Uji Koefisien Determinasi}

\section{Model Summary}

\begin{tabular}{|l|l|r|r|r|}
\hline & \multicolumn{4}{|c|}{ Adjusted $R$ Std. Error of } \\
\hline Model & $\mathrm{R}$ & $R$ Square & Square & the Estimate \\
\hline 1 & $811^{a}$ &, 657 &, 652 &, 21829 \\
\hline
\end{tabular}

a. Predictors: (Constant), PH, JP, PDRB

b. Dependent Variable: PAD

Sumber: Data Diolah Penulis, Tahun 2018

Berdasarkan hasil uji koefisien determinasi pada Tabel 7 di atas bahwa nilai Adjusted $R$
Square sebesar 0,652 atau sebesar 65,2\%. Hal ini menunjukkan bahwa presentase pengaruh variable independen (Produk Domestik Regional Bruto, Jumlah Penduduk Dan Pajak Hotel) terhadap variabel dependen (Pendapatan Asli Daerah) sebesar 65,2\%, sisanya $34,8 \%$ dipengaruhi oleh variabel lain yang tidak dimasukkan dalam penelitian ini atau faktorfaktor lain yang terdiri dari pajak daerah, inflasi, jumlah wisatawan, dan pajak restoran.

\section{Uji t (Uji Parsial)}

Tabel 7 di bawah ini merupakan hasil uji $\mathrm{t}$ (uji parsial) dari penelitian ini.

\section{Tabel 7}

\section{Hasil Uji Parsial}

Coefficient

\begin{tabular}{|l|l|r|r|}
\hline Model & & \multicolumn{1}{c|}{$t$} & \multicolumn{1}{c|}{ Sig. } \\
\hline \multirow{3}{*}{1} & $($ Constant $)$ & 25,998 &, 000 \\
\cline { 2 - 4 } & PDRB & 7,260 &, 000 \\
\cline { 2 - 4 } & JP & 6,397 &, 000 \\
\hline & PH & 8,954 &, 000 \\
\hline
\end{tabular}

a. Dependent Variable: PAD Sumber:

Data Diolah Penulis, Tahun 2018

Untuk mencari t-tabel menggunakan rumus $\mathrm{df}=\mathrm{n}-\mathrm{k}-1$ dimana $\mathrm{n}=$ jumlah sampel dan $\mathrm{k}=$ jumlah variabel independen, sehingga di dapat df $=230-3-1=226$, dengan menggunakan taraf signifikansi 0,05 diperoleh t-tabel sebesar 1,970516 .

Berdasarkan Tabel 7 uji t (Uji Parsial) dapat diketahui bahwa variabel produk domestik regional bruto memiliki t-hitung sebesar 7,260 sedangkan ttabel sebesar 1,970516 maka t-hitung > t-tabel dengan signifikansi $0,000<0,05$. Hal ini menunjukkan bahwa Ho ditolak dan $\mathrm{Ha}$

ISSN: 
diterima, sehingga dapat disimpulkan bahwa produk domestik regional bruto berpengaruh signifikan positif terhadap pendapatan asli daerah. Besar kecilnya produk domestik regional bruto, berpengaruh pada tinggi rendahnya pendapatan asli daerah.

Berdasarkan Tabel 7 uji t (Uji Parsial) dapat diketahui bahwa variabel jumlah penduduk memiliki thitung sebesar 6,397 sedangkan t-tabel sebesar 1,970516 maka t-hitung > t-tabel dengan signifikansi $0,000<0,05$. Hal ini menunjukkan bahwa Ho ditolak dan Ha diterima, sehingga dapat disimpulkan bahwa jumlah penduduk

berpengaruh signifikan positif terhadap pendapatan asli daerah. Banyak sedikitnya jumlah penduduk, berpengaruh pada tinggi rendahnya pendapatan asli daerah.

Berdasarkan Tabel 7 uji t (Uji Parsial) dapat diketahui bahwa variabel pajak hotel memiliki thitung sebesar 8,954 sedangkan t-tabel sebesar 1,970516 maka thitung > t-tabel dengan signifikansi $0,000<0,05$. Hal ini menunjukkan bahwa Ho ditolak dan Ha diterima, sehingga dapat disimpulkan bahwa pajak hotel

berpengaruh signifikan positif terhadap pendapatan asli daerah. Besar kecilnya pajak hotel, berpengaruh pada tinggi rendahnya pendapatan asli daerah.

\section{Model Regresi Linear Berganda}

Berdasarkan Tabel 8 di dawah ini, maka diperoleh persamaan regresi sebagai berikut:

$$
\begin{gathered}
\mathrm{PAD}=15,577+0,230 \mathrm{PDRB}+0,234 \mathrm{JP}+ \\
0,095 \mathrm{PH}
\end{gathered}
$$

Dari persamaan regresi di atas, diketahui bahwa nilai konstanta yang didapat sebesar
15,577 artinya jika PDRB, jumlah penduduk, dan pajak hotel ada maka pendapatan asli daerah akan meningkat sebesar 15,577 \% .

\section{Tabel 8}

\section{Hasil Uji Regresi Linear Berganda}

Coefficient

\begin{tabular}{|l|r|r|r|}
\hline & \multicolumn{2}{|c|}{ Coefficients $^{a}$} & \\
\hline \multirow{3}{*}{ Model } & \multicolumn{2}{|c|}{$\begin{array}{l}\text { Unstandardized } \\
\text { Coefficients }\end{array}$} & $\begin{array}{c}\text { Standardized } \\
\text { Coefficients }\end{array}$ \\
\cline { 2 - 5 } & $B$ & Std. Error & Beta \\
\hline 1 (Constant) & 15,577 &, 599 &, 371 \\
\hline PDRB &, 230 &, 032 &, 296 \\
\hline JP &, 234 &, 037 &, 393 \\
\hline PH &, 095 &, 011 & \\
\hline
\end{tabular}

Dependent Variable: PAD

Sumber: Data Diolah Penulis, Tahun 2018

Variabel produk domestik regional bruto memiliki koefisien regresi sebesar 0,230 menyatakan bahwa setiap kenaikan $1 \%$ produk domestik regional bruto (dengan asumsi bahwa nilai koefisien variabel lain tetap), maka akan meningkatkan nilai terhadap pendapatan asli daerah sebesar $0,230 \%$. Koefisien positif berarti terjadi hubungan positif antara produk domestik regional bruto dengan pendapatan asli daerah.

Variabel jumalah penduduk memiliki koefisien regresi sebesar 0,234 menyatakan bahwa setiap kenaikan $1 \%$ jumlah penduduk (dengan asumsi bahwa nilai koefisien variable lain tetap), maka akan meningkatkan nilai terhadap pendapatan asli daerah sebesar 0,234\%. Koefisien positif berarti terjadi hubungan positif antara jumlah penduduk dengan pendapatan asli daerah.

Variabel pajak hotel memiliki koefisien regresi sebesar 0,095 menyatakan bahwa setiap kenaikan $1 \%$ pajak hotel (dengan asumsi bahwa

ISSN: 
nilai koefisien variabel lain tetap), maka akan meningkatkan nilai terhadap pendapatan asli daerah sebesar 0,095\%. Koefisien positif berarti terjadi hubungan positif antara pajak hotel dengan pendapatan asli daerah.

\section{KESIMPULAN DAN SARAN}

\section{Simpulan}

Hasil penelitian menunjukkan bahwa produk domestik regional bruto, jumlah penduduk, dan pajak hotel berpengaruh signifikan positif terhadap pendapatan asli daerah.

Hasil pengujian koefisien determinasi menunjukkan bahwa produk domestik regional bruto, jumlah penduduk, dan pajak hotel mempunyai pengaruh sebesar $65,2 \%$ terhadap. pendapatan asli daerah, sisanya $34,8 \%$ dipengaruhi oleh variabel lain yang tidak dimasukkan kedalam penelitian ini.

\section{Implikasi}

Peneliti selanjutnya di sarankan dapat melakukan penelitian dengan penambahan variabel independen yang berbeda dalam mempengaruhi pendapatan asli daerah dan dapat melakukan penelitian dengan data atau sampel dalam rentang waktu yang lebih panjang serta populasi yang lebih luas.

Pemerintah di sarankan lebih tegas dalam membuat aturan mengenai kepatuhan terhadap pembayaran pajak dan pemerintah lebih meningkatkan sumber pendapatan asli daerah dari berbagai sektor yang sekiranya masih

kurang memberikan kontribusinya agar penerimaan pendapatan asli daerah kedepannya dapat lebih optimal.

Untuk masyarakat dan para pengusaha di sarankan untuk taat dalam membayar pajak sesuai dengan ketentuan yang telah ditetapkan pemerintah daerah agar pendapatan asli daerah dapat meningkat.

\section{Keterbatasan}

Hasil dari penelitian ini terdapat keterbatasan, yaitu karena kekurangan sampel, maka peneliti harus beberapa kali mengganti populasi dan kriteria pengambilan sampel.

\section{DAFTAR PUSTAKA}

Undang-Undang Republik Indonesia Nomor 23 Tahun 2014 Tentang Pemerintah Daerah. (2014). Jakarta.

Undang-Undang Republik Indonesia Nomor 28 Tahun 2009 Tentang Pajak Daerah Dan Retribusi Daerah. (2009). Jakarta.

Undang-Undang Republik Indonesia Nomor 33 Tahun 2004 Tentang Perimbangan Keuangan Antara Pemerintah Pusat Dan Pemerintah Daerah. (2004). Jakarta.

Undang-Undang Republik Indonesia Nomor 52 Tahun 2009 Tentang Perkembangan Kependudukan Dan Pembangunan Keluarga. (2009). Jakarta.

Al-zeaud, H. A. (2015). The Causal Relationship Between Government Revenue and Expenditure in Jordan, Int. J. Manag. Bus. Vol. 5, no. 2, pp. 117-127.

Asmuruf, M.F., Rumate,V.A., \& Kawung, G.M.V. (2015). Pengaruh Pendapatan dan Jumlah Penduduk Terhadap Pendapatan Asli Daerah (PAD) di Kota Sorong, Jurnal Berkala Ilmiah Efisiensi, vol. 15, no. 05.

Batik, Karlina. (2013). Analisis Pengaruh Investasi, PDRB, Jumlah Penduduk, Penerimaan Pembangunan, dan Inflasi Terhadap Pendapatan Asli Daerah (PAD) di

ISSN: 
Kabupaten Lombok Barat, Jurnal Ekonomi Pembangunan, vol. 11, no. 01, Juni 2013.

Bawono, I.R., \& Novelsyah, M., (2012). Tata Cara Penatausahaan Dan Pertanggungjawaban Bendahara Pada SKPD Dan SKPKD, Salemba Empat.

Ghozali, I., (2016). Aplikasi Analisis Multivariete Dengan Program IBM SPSS 23, Badan Penerbit Universitas Diponegoro, Semarang.

Hamdani, (2016). Good Corporate Governance: Tinjauan Etika Dalam Praktik Bisnis, Mitra Wacana Media, Jakarta.

Jaya,G.B.P., \& Widanta, A.A.B.P. (2014). Analisis Faktor-faktor yang Berpengaruh Terhadap Pendapatan Asli Daerah (PAD) Kota Denpasar, E-Jurnal Ekonomi Pembangunan Universitas Udayana, vol. 3, no. 5, Mei 2014.

Kota Tasikmalaya Dalam Angka diakses pada tanggal 17 September 2017 dari www.tasikmalaya.bps.go.id

Laporan Keuangan Pemerintah Daerah Kota Tasikmalaya (2015). Badan Pemeriksa Keuangan Republik Indonesia, Jakarta.

Liliana,B., Diana, M., \& Carmen, C. (2011). Is There A Correlation Between Governance Expenditures, Population, Money Supply And Goverment Revenue, International Journal Of Arts \& Sciences.

Marliyanti, D.S., \& Arka, S. (2014). Pengaruh PDRB Terhadap Pajak Daerah dan Pendapatan Asli Daerah (PAD) Kota Denpasar, E-Jurnal Ekonomi Pembangunan Universitas Udayana, vol. 3, no. 6, Juni 2014.

Mayza, M., Masbar, R., \& Nasir, M. (2015). Analisis Faktor-faktor yang Mempengaruhi Pendapatan Asli Daerah (PAD) Provinsi Aceh, Jurnal Ilmu Ekonomi Pascasarjana Universitas Syiah Kuala, vol. 3, no. 1, Februari 2015.

Muchtolifah.(2010). Pengaruh Produk Domestik
Bruto (PDRB), Inflasi, Investasi Industri dan Jumlah Tenaga Kerja Terhadap Pendapatan Asli Daerah (PAD) di Kota Mojokerto. Jurnal Ilmu Ekonomi Pembangunan. Vol. 1, hlm. 35-37.

Murib, P., Rotinsulu, D.C., \& Tolosong, K.D. (2016). Pengaruh Pendapatan Perkapital, Jumlah Perusahaan dan Jumlah Penduduk Terhadap Pendapatan Asli Daerah di Kabupaten Narbire Papua Tahun 2004-2013, Jurnal Berkala Ilmiah Efisiensi, vol. 16, no. 01, 2016.

Pedoman Praktis Perhitungan PDRB Kabupaten/ Kota, (2008). Pengertian dasar diakses pada tanggal 22 September 2017 dari http:// www.bps.go.id

Prayanti, N.L.P.A., Suwendra, W., \& Yudiaatmaja, F. (2014). Pengaruh Penerimaan Pajak Hotel, Pajak Restoran dan Retribusi Daerah Terhadap Pendapatan Asli Daerah Kabupaten Bandung Tahun 2010-

2013, E-Jurnal Bisma Universitas Pendidikan Ganesha Jurusan Manajemen, vol. 2, 2014.

Priantara, D., (2013). Perpajakan Indonesia (Pembahasan Lengkap \& Terkini Disertai CD Praktikum) Edisi 2 Revisi, Mitra Wacana Media, Jakarta.

Produk Domestik Regional Bruto Menurut Lapangan Usaha DKI Jakarta 2010-2014 di akses pada tanggal 11 Oktober 2017 dari https://jakarta.bps.go.id/

Puspitasari, A.W., Suhadak, \& Handayani, S.G. (2015). Pengaruh Pertumbuhan Pajak Daerah Terhadap Peningkatan Penerimaan Pendapatan Asli Daerah (Studi pada Pajak Hotel, Pajak Restoran dan Pajak Hiburan Kabupaten Tulungagung Tahun 2012-2014), Jurnal Administrasi Bisnis-Perpajakan, vol.5, no. 2, 2015.

Rusdianto, U., (2013). CSR Communication A Framework For PR Practitioners, Graha Ilmu, Yogyakarta.

Rustanto, E.A., Nurlaela, S., \& Wijayati, A. (2013). Pengaruh Pajak Hotel dan Pajak

ISSN:

2302-1810 (online)

DOI: http://doi.org/10.21009/wahanaakuntansi/13.1.05 
Restoran Terhadap Pendapatan Asli Daerah Kota Surakarta, Jurnal Paradigma, vol. 11, no. 02, Agustus 2013, hlm. 44.

Sarwono, Jonathan. (2015). Rumus-Rumus Populer Dalam SPSS 22 Untuk Riset Skripsi, C.V ANDI OFFSET, Yogyakarta.

Suartini, N.N., \& Surya, U.M. (2013). Pengaruh Jumlah Kunjungan Wisatawan, Pajak Hiburan, Pajak Hotel dan Restoran Terhadap Pendapatan Asli Daerah di Kabupaten Gianyar, E-Jurnal Ekonomi dan Bisnis Universitas Udayana, vol. 02, no. 03, 2013.

Widiyaningsih, P., \& Budhi, M.K.S. (2014). Pengaruh Jumlah Kunjungan Wisatawan Terhadap Penerimaan Pajak Hotel, Pajak Restoran dan Pendapatan Asli Daerah, EJurnal EP Unud, vol.3, no. 4, 2014, hlm. 155-163.

Wulandari, P.A.,\& Iryanie, E. (2016). Analisis Pengaruh Kontribusi Pajak Daerah Terhadap Pendapatan Asli Daerah (PAD) Kota Banjarmasin, Prosiding Seminar Nasional INDOCOMPAC, 2-3 Mei 2016.

Wulandari, P.P., \& Ayuningsasi, A.A.K. (2014). Analisis Variabel-Variabel yang Mempengaruhi Pendapatan Asli Daerah Provinsi Bali, E-Jurnal Ekonomi Pembangunan Universitas Udayana, vol. 3, no. 11, November 2014. 